\title{
PARTICIPACIÓN DEL ALUMNADO EN LA EVALUACIÓN EN SECUNDARIA
}

\author{
Student participation in assessment in Secondary Education \\ Participação dos alunos na avaliação no Ensino Secundário
}

\section{Teresa Fuentes Nieto (1)}

(1) IES Marqués de Lozoya, Cuéllar, Segovia, Spain. fuentes.teresa@gmail.com

\section{Resumen}

La participación en la evaluación por parte de los alumnos es uno de los pilares de la evaluación formativa y compartida. En esta mesa redonda aportaré mi experiencia en la asignatura de Educación Física en la etapa de secundaria, dónde he trabajando los últimos 4 años en 3 centros diferentes de Castilla y León. Cada vez son más los profesores que abogan por una evaluación en la que participen los alumnos. La participación de los alumnos en la evaluación en la etapa de secundaria se lleva a en diferentes momentos (inicial, continua, final, con instrumentos variados (rutinas de pensamiento, kahoot, rúbricas...) y de manera más o menos formal (lluvia de ideas, feedback entre iguales, rúbricas de autoevaluación, etc.).

Palabras-clave: Evaluación; educación secundaria; participación del alumno; educación física

\begin{abstract}
Student participation in assessment is one of the pillars of the formative and shared assessment. In this round table, I would like to share my experience in the subject of Physical Education in secondary, where I have been working the last 4 years in 3 different high schools of Castilla y León. More and more teachers are advocating an assessment in which students participate. The participation of the students in the assessment in the secondary is carried out in different moments (initial, continuous, final), with several instruments (routines of thought, quiz, rubrics ...) and in a more or less formal way (rain of ideas, feedback between equals ...).

Keywords: Assessment; Secondary Education; student participation; physical education.
\end{abstract}




\section{Resumo}

A participação dos alunos na avaliação é um dos pilares da avaliação formativa e partilhada. Nesta mesa redonda trarei minha experiência na disciplina de Educação Física no ensino secundário, onde trabalhei os últimos quatro anos, em três centros diferentes de Castilla y León. Cada vez são mais os professores que defendem o uso de uma avaliação, na qual participem os alunos. A participação dos alunos na avaliação no ensino secundário acontece em diferentes momentos (inicial, contínua, final), com instrumentos variados (rutinas de pensamento, kahoot, rubricas...) e de maneira mais ou menos formal (brainstorming, feedback entre pares, rubricas de autoavaliação, etc.).

Palavras-chave: Avaliação; Ensino secundário; participação dos alunos; educação física

\section{Contexto}

Mi valoración y discusión sobre la participación del alumnado en la evaluación se centra en la etapa de secundaria, en la asignatura de educación física. Durante los últimos 4 años he impartido esta asignatura en 3 centros diferentes en alumnado de ESO y $1^{\circ}$ de bachillerato. Debemos tener en cuenta que se trata de una asignatura obligatoria con una carga lectiva de dos sesiones semanales (unos 50 minutos por sesión) y con unas características particulares. Es una asignatura eminentemente procedimental lo cual influye en el diseño de su evaluación.

\section{La evaluación formativa y compartida en Educación Secundaria en Educación}

\section{Física}

El paradigma educativo actual sitúa al alumno en el centro del proceso de aprendizaje y como tal, la evaluación es uno de los procesos en los que el alumno ha de implicarse para hacerse responsable de su propio aprendizaje. La evaluación compartida tiene entre sus características fundamentales la participación de los alumnos en el proceso de evaluación del aprendizaje.

Durante estos años mi percepción personal es que la implantación de una evaluación formativa y compartida en secundaria se está llevando a cabo poco a poco y cada vez son más los profesores que han oído hablar de ella, conocen sus bases y/o la están aplicando (Fuentes y López, 2017). No obstante su implantación de manera generalizada aún está por llegar (López-Pastor et al., 2013, López, 2013). 
Para exponer algunos ejemplos de cómo se está llevando a cabo esta participación del alumno en la evaluación es necesario puntualizar que la evaluación formativa se lleva a cabo durante todo el proceso de aprendizaje y no de manera puntual al final de una unidad didáctica concreta (López-Pastor, 2006).

La planificación del contenido propio de las asignaturas, y concretamente de educación física, se realiza a través de unidades didácticas, que suelen abarcar unas 8-10 sesiones. Podemos distinguir 3 tipos o momentos en los que se lleva a cabo la evaluación formativa y compartida: inicial, continua y final. Aunque no siempre se dan las tres en cada UD.

Las técnicas utilizadas para la participación de los alumnos en la evaluación varían en función de: el profesor, los contenidos, el alumnado, los medios informáticos y audiovisuales, el momento de la unidad didáctica, etc.

A continuación se exponen algunas de las técnicas e instrumentos utilizadas por los alumnos cuando participan en la evaluación, teniendo en cuenta el momento de la misma:

- Evaluación inicial (conocimientos previos):

- Pruebas estructuradas escritas en soporte analógico: test, preguntas cortas, rutinas de pensamiento, etc.

- Preguntas estructuradas en soporte digital a modo de juego o concurso: kahoot, plickers, etc.

- Preguntas no estructuradas orales y/o escritas: lluvia de ideas, preguntas orales, etc.

- Evaluación continua (comprobación del aprendizaje que se está llevando a cabo):

- Realización de rúbricas y fichas de autoevaluación y coevaluación de los aprendizajes llevados a cabo hasta ese momento.

- Feedback entre iguales.

- Evaluación final (evidencias de los aprendizajes):

- Realización de rúbricas y fichas de autoevaluación y coevaluación que incluyen la evaluación de todos los aprendizajes de la UD.

- Visualización de las producciones de los alumnos (videos tutoriales, exposiciones orales o composiciones finales) que reflejen los aprendizajes adquiridos. 
En cualquier caso, cualquiera de los ejemplos expuestos anteriormente requiere una reflexión por parte del alumno sobre el proceso de aprendizaje. El alumno debe analizar su propio aprendizaje de manera consciente para hablar de "participación real del alumno" en el proceso de evaluación.

Creo que la participación del alumnado en el diseño de la evaluación no se lleva acabo con asiduidad, ya que normalmente el profesor tiene diseñados de antemano los criterios de evaluación y no suele revisar los mismos hasta concluida la UD.

Por otro lado, es más sencilla la participación de los alumnos en la evaluación del diseño de la UD una vez concluida la misma. Este proceso es muy enriquecedor y ayuda al profesor a ajustar las UUDD a los objetivos de aprendizaje deseados.

\section{Conclusiones}

Desde mi punto de vista, la inclusión paulatina de la evaluación formativa y compartida en la etapa de secundaria ha hecho que la participación del alumnado en la evaluación sea cada vez más relevante. Muchos profesores están aplicando diferentes técnicas, estrategias e instrumentos para que el alumno participe en la evaluación en educación física. No obstante, aún queda mucho por avanzar para que la mayoría de los profesores lo lleve a cabo.

Personalmente encuentro que la participación del alumnado en la evaluación del proceso de enseñanza-aprendizaje encaja con el paradigma educativo que pone como protagonista al alumno, desde el que intento llevar a cabo mi labor docente.

Mi experiencia implementando poco a poco la participación del alumno en la evaluación es positiva, encuentro muchas ventajas al respecto, entre las que destaco:

-Un incremento de la conexión entre profesor y alumno. El alumno siente que su valoración importa y que el profesor le tiene en cuenta lo cual mejora la relación docente-discente.

-Se potencia la responsabilidad del alumno en su propio aprendizaje. Creo que la participación del alumno en la evaluación favorece la madurez del alumnado.

-Hay un ajuste en el diseño de la UD, el profesor cuenta con la información de los alumnos para mejorar el diseño de las UD.

No podemos olvidar que el diseño de UUDD que contemplen la participación del alumnado en la evaluación supone un cambio en la estructura "tradicional" de las mismas y un esfuerzo por parte del profesor para su planificación. Considero que es 
muy complicado cambiar toda la programación anual de un año para otro, pero sí es viable ir modificando paulatinamente el diseño de las UUDD e ir introduciendo así la “cultura de participación" a los alumnos, de manera que cada curso sumamos "buenas experiencias", siendo más coherentes con nuestra labor docente.

Creo que merece la pena fomentar la participación del alumnado en la evaluación y en mi trabajo intento ir introduciendo en mis UUDD los recursos necesarios para ello. Creo que este proceso proporciona una motivación en el profesor que compensa el trabajo invertido.

\section{Referencias}

Fuentes, T.; López-Pastor, V. M. (2017). Evaluación auténtica, coevaluación y uso de las TIC en educación física: un estudio de caso en secundaria. Infancia, Educación y Aprendizaje (IEYA), 3(2); 42-46. ISSN: 0719-6202. http://revistas.uv.cl/index.php/IEYA/index.

López-Pastor VM, Kirk D, Lorente-Catalán E, MacPhail A and Macdonald D (2013) Alternative Assessment in Physical Education: A Review of International Literature. Sport, Education \& Society, 18(1), 57-76. DOI:10.1080/13573322.2012.713860.

López-Pastor VM (2013) Nuevas perspectivas sobre Evaluación en Educación Física. Revista de Educación Física, 29(3): 4-13.

López-Pastor VM (coord.) (2006) La Evaluación en Educación Física: revisión de los modelos tradicionales y planteamiento de una alternativa: la Evaluación Formativa y Compartida. Buenos Aires: Miño y Dávila. 